\title{
Salvianolic acid A positively regulates PTEN protein level and inhibits growth of A549 lung cancer cells
}

\author{
LEI BI $^{1 *}$, JIANPING CHEN $^{2 *}$, XIAOJING YUAN $^{2}$, ZEQUN JIANG $^{2}$ and WEIPING CHEN ${ }^{2}$ \\ ${ }^{1}$ The Associated Hospital of Nanjing University of Chinese Medicine; ${ }^{2}$ College of Basic Medicine, \\ Nanjing University of Chinese Medicine, Nanjing 210046, P.R. China
}

Received August 26, 2012; Accepted October 12, 2012

DOI: $10.3892 /$ br.2012.33

\begin{abstract}
Salvianolic acid A (Sal A) is an effective compound extracted from Salvia miltiorrhiza which has been used in the treatment of various diseases. Preliminary data indicate that Sal A treatment has a specific anti-lung cancer effect. However, the manner in which Sal A regulates cancer growth remains unknown. In this study, the A549 lung cancer cell line and its response to Sal A treatment was examined. Results showed that Sal A treatment significantly decreased A549 cell growth, promoted partial apoptosis and increased mitochondrial membrane permeability. Western blot analysis showed that Sal A upregulated the phosphatase and tensin homolog (PTEN) protein level, while consistently downregulating Akt phosphorylation. These results indicate that Sal A negatively mediates A549 lung cancer cell line growth or apoptosis, most likely by positively regulating PTEN protein level.
\end{abstract}

\section{Introduction}

Salvia miltiorrhizae has been used effectively as medicine in China for treatment against various diseases (1). Besides other compounds with clinical significance purified from Salvia miltiorrhizae, salvianolic acid A (Sal A), one of the soluble components has demonstrated various physiological characteristics including anti-cruor, anti-platelet aggregation and anticancer (2). Its molecular formula is shown in Fig. 1. The combination of Sal A and other drugs, such as 5-Fluorouracil, Mitomycin $\mathrm{C}$ and Methotrexate, results in the inhibition of cancer growth (3). Preliminary data have indicated that Sal A is able to inhibit cancer growth in mouse models, including liver, breast and lung cancers. The mechanism of action of Sal A in the regulation of cancer cell growth has yet to be elucidated.

Correspondence to: Dr Weiping Chen, College of Basic Medicine, Nanjing University of Chinese Medicine, 138 Xianlin Road, Nanjing 210046, P.R. China

E-mail:wp2002123@163.com

*Contributed equally

Key words: salvianolic acid A, apoptosis, phosphatase and tensin homolog, Akt phosphorylation
Phosphoinositide 3-kinase (PI3K)/Akt signaling pathway is essential in the regulation of cell survival, growth, differentiation, apoptosis and autophagy (4). Activation of PI3K phosphorylates phosphatidylinositol (4,5)-bisphosphate (PIP2) by converting it into phosphatidylinositol $(3,4,5)$-triphosphate (PIP3), thereby preventing cell apoptosis or autophagy. Akt, a key kinase downstream of PI3K in the signaling pathway, is involved in regulating cell status (5). There are three homologies of Akt in mammalian cells. Of those, Akt1 is pathologically expressed in human cancer cells, suggesting its direct involvement in cancer onset or development (6). Multiple causes of oncogenic transformation are involved in the regulation of Akt activity $(7,8)$. The enhanced Akt activity and the downstream signaling strength result in the Akt-dependent suppression of apoptosis and differentiation, but increase the cell cycle progression (9).

Phosphatase and tensin homolog (PTEN) deleted on chromosome 10 , acts as a phosphatase to dephosphorylate its substrates, causing tumor suppressor (10). This phosphatase is involved in the regulation of the cell cycle by inhibiting cell growth and division. PTEN as a lipid phosphatase is localized on the membrane (11). In the cytoplasm, PTEN inhibited PI3K signaling by transforming PIP3 into PIP2 (12). Due to the lack of PTEN in cytoplasm, PIP3 was accumulated, both Akts and phosphoinositide-dependent kinase-1 (PDK1) contain a PH domain that binds to membrane-bound PIP3. Once in the membrane, PDK1 and mammalian target of rapamycin 1 (mTOR1) activate Akt through phosphorylation at various sites. Thus, the activated Akt positively regulated cell growth or activity, but negatively regulated cell autophagy and apoptosis (13). PTEN has been demonstrated to be the essential molecule regulating PI3K/AKT pathways and consequently various cell destinations (14).

In this study, the A549 lung cancer cell line and its response to Sal A treatment was examined. Results showed that Sal A inhibits growth of the A549 lung cancer cell line, induces the trend of apoptosis and at the molecular level, regulates PI3K/ AKT signaling pathway by positively mediating PTEN protein stability.

\section{Materials and methods}

Cell culture and 3-(4,5-dimethylthiazol-2-yl)-2,5-diphenyltetrazolium bromide (MTT). A549 cells were purchased from 
the Shanghai Cell Research Institute of the China Academy. Cells were cultured in media with $10 \%$ Fas, at $37^{\circ} \mathrm{C}$ with $5 \%$ $\mathrm{CO}_{2}$. Cells were grown to $80 \%$ confluence, then digested with $0.25 \%$ trypsin and transferred into a new plate with fresh media. For MTT, cells were seeded in 96-well plates with $3 \times 10^{3}$ cells/well. The cells were collected at various time points and Sal A doses of $20 \mu 1 \mathrm{MTT}(5 \mathrm{mg} / \mathrm{ml})$ were added to each well prior to reaction for $4 \mathrm{~h}$. The supernatant was removed, the pellet was resuspended and $150 \mu 1$ dimethyl sulfoxide (DMSO) were added to each well, followed by agitation at room temperature for $15 \mathrm{~min}$ to dissolve the precipitates. The absorbance (A) value was measured at $490 \mathrm{~nm}$. The inhibition ratio was calculated as: the inhibition ratio of cell growth $=(1-$ value $\mathrm{A}$ of each sample/value $\mathrm{A}$ of control) x $100 \%$.

Flow cytometry analysis. A549 cells were transferred to a 6-well plate with $2 \times 10^{5} / \mathrm{ml}$ and cultured at $37^{\circ} \mathrm{C}$, with $5 \% \mathrm{CO}_{2}$ for $24 \mathrm{~h}$, followed by Sal A treatment at the concentrations of 10,30 and $60 \mu \mathrm{g} / \mathrm{ml}$, respectively. The control group was free of the treatment. After $12 \mathrm{~h}$ of culturing, cells were stripped with $0.25 \%$ trypsin and collected by centrifugation (1000 rpm) at $4^{\circ} \mathrm{C}$ for $5 \mathrm{~min}$. The pellets were washed again with cold phosphate-buffered saline (PBS), following the addition of $500 \mu \mathrm{l}$ binding buffer for cell suspension. The pellets were then mixed with $5 \mu \mathrm{l}$ Annexin V-FITC and $5 \mu \mathrm{l}$ propidium iodide for $10 \mathrm{~min}$ in the dark and flow cytometer was employed to determine the apoptosis ratio.

Measurement of A549 permeability during Sal A treatment. After 24-h Sal A treatment A549 cells were washed three times with PBS and mixed with $0.1 \mu \mathrm{M}$ MitoTracker ${ }^{\circledR}$ and $10 \mathrm{nM}$ Hoechst for staining. After 30 -min reaction at $37^{\circ} \mathrm{C}$, the mixture was washed with PBS three more times, and fixed with 4\%-paraformaldehyde for $15 \mathrm{~min}$. For the staining procedure, cells were washed with PBS three times and $150 \mu 1$ PBS was then added. Cell Health Profiling software was applied to analyze the results of Thermo Cellomics ${ }^{\circledR}$ ArrayScan ${ }^{\circledR}$ VTi.

Western blot analysis. A549 cells were washed twice with ice-cold PBS and lysed in cold lysis buffer [ $40 \mathrm{mmol} / 1 \mathrm{HEPES}$, $\mathrm{pH} 7.5,150 \mathrm{mmol} / 1 \mathrm{NaCl}, 1.5 \mathrm{mmol} / 1 \mathrm{MgCl}_{2}, 1 \mathrm{mmol} / \mathrm{l}$ ethylenediaminetetraacetic acid (EDTA), $1 \mathrm{mmol} / 1$ dithiothreitol and $1 \mathrm{mmol} / \mathrm{l}$ fresh phenylmethylsulfonyl fluoride]. Lysates were incubated for $20 \mathrm{~min}$ on ice and centrifuged at $12000 \mathrm{x} \mathrm{g}$ for $15 \mathrm{~min}$. The supernatant was collected, and the protein concentration was determined by Lowry protein assay. The protein was electrophoresed by sodium dodecyl sulfate polyacrylamide gel electrophoresis (SDS-PAGE) and then transferred onto polyvinylidene fluoride (PVDF) membranes. The membranes were blocked with $50 \mathrm{~g} / \mathrm{l} \mathrm{non-fat}$ dried milk in PBST (PBS, $0.5 \mathrm{ml} / 1$ Tween-20) for $2 \mathrm{~h}$ at room temperature and incubated overnight at $4^{\circ} \mathrm{C}$ with the first antibody against human PTEN, caspase-3 and a phosphorylated antibody against AKT (first antibodies were purchased from Bioworlde, St. Louis Park, MN, USA), followed by incubation with an HRP-conjugated secondary antibody (Bioworlde) at room temperature for $1 \mathrm{~h}$. Enhanced chemiluminescence (ECL) was used to detect the results.
Table I. A549 growth decreased under Sal A treatment.

\begin{tabular}{lrrrrr}
\hline \multirow{2}{*}{$\begin{array}{l}\text { Inhibitory } \\
\text { ratio }(\mathrm{h})\end{array}$} & \multicolumn{5}{c}{ Concentrations } \\
\cline { 2 - 6 } & \multicolumn{1}{c}{0.01} & \multicolumn{1}{c}{0.1} & 1 & 10 & 100 \\
\hline 24 & 2.95 & 4.10 & 10.00 & 13.29 & 96.79 \\
48 & 34.14 & 38.96 & 40.76 & 40.11 & 89.95 \\
72 & 9.00 & 4.36 & 5.37 & 12.93 & 89.98 \\
\hline
\end{tabular}

A549 cells were treated with Sal A at various concentrations, including $0.01,0.1,1,10$ and $100 \mu \mathrm{g} / \mathrm{ml}$, respectively. Cells were counted at various time points $(12,24$ and $72 \mathrm{~h}$ ) after treatment, and the inhibitory ratio was calculated. Sal A, salvianolic acid A.

Figure 1. Molecular formula of salvianolic acid A ( $\mathrm{Sal} \mathrm{A})$ is shown. Sal A is a soluble compound.

\section{Results}

Sal A had a negative effect on A549 cell growth. The A549 lung cancer cell line was used as a model system to examine the effect of Sal A on its growth. A549 cells were treated with Sal A at various concentrations of $0.01,0.1,1,10$ and $100 \mu \mathrm{g} / \mathrm{ml}$, respectively. At various time points after treatment, cells were counted and the results showed that cell growth decreased at the concentration of $\geq 10 \mu \mathrm{g} / \mathrm{ml}$ (Table I). With the increase of Sal A concentration, cell growth was significantly retarded. At $100 \mu \mathrm{g} / \mathrm{ml}$, the inhibitory ratio of cell growth was $\sim 90 \%$. At $12 \mathrm{~h}$ treatment, cells became abnormal and floated. At $48 \mathrm{~h}$, cell death ratio was the highest. However, at $72 \mathrm{~h}$, cells demonstrated continued growth. This suggested that the growth-inhibitory effect of Sal A was concentration- and time-dependent in the A549 lung cancer cell line.

Sal A induced $A 549$ cell apoptosis. There are multiple locations for treated cells following cell growth inhibition. For instance, cells may undergo autophagy, apoptosis, cell silence or even cell differentiation. To determine the biological consequence of Sal A treatment on A549 cells, flow cytometry was used to examine the cell phases during Sal A treatment. The results showed that cell growth was mostly blocked at G1 phase (data not shown). In addition, at low concentration $(10 \mu \mathrm{g} / \mathrm{ml}),>16 \%$ cells underwent apoptosis (including apoptosis at the earlyand late-stages). With the addition of Sal A the apoptotic rate increased. At high concentrations $(30 \mu \mathrm{g} / \mathrm{ml})$, the apoptotic rate was only $6 \%$, however, most cells were floating and 
A
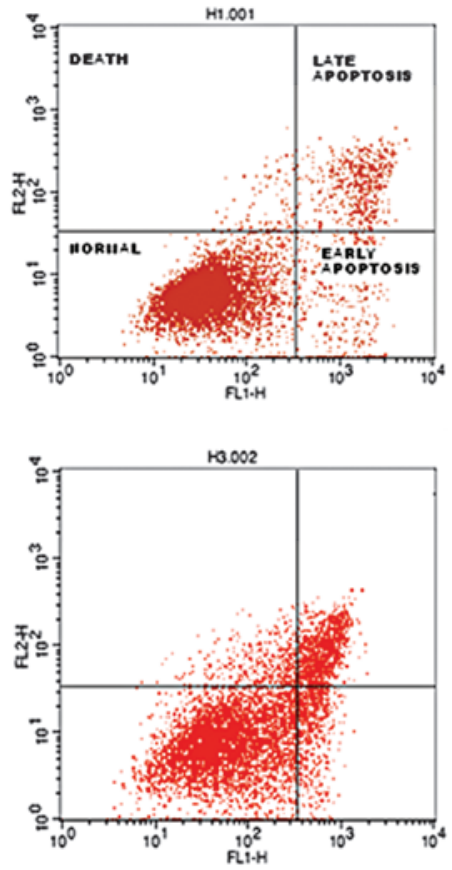
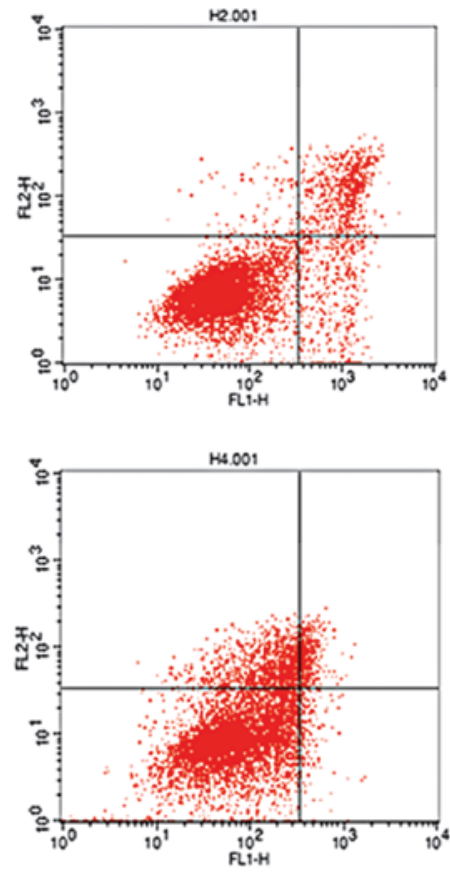

B

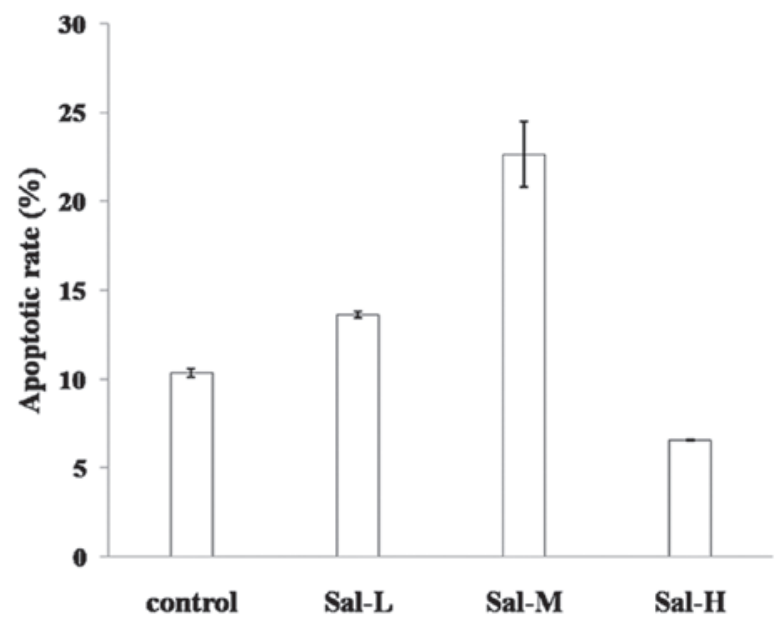

Figure 2. A549 apoptotic rate to total cells under salvianolic acid A ( $\mathrm{Sal} \mathrm{A}$ ) treatment is shown. A549 cells were collected at $24 \mathrm{~h}$ after Sal A treatment at concentrations of 10,20 and $30 \mu \mathrm{g} / \mathrm{ml}$, respectively. (A) Flow cytometry analysis was used to examine the apoptotic ratio of A549. (B) Results of three experiments were analyzed using the Student's t-test $(\mathrm{P}<0.01)$. Sal-L, Sal-M and Sal H are the concentrations of 10, 20 and $30 \mu \mathrm{g} / \mathrm{ml}$, repectively.

A

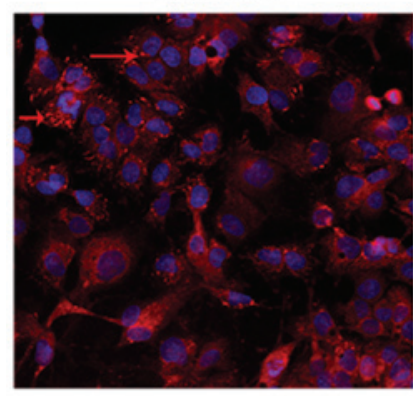

$20 \mu \mathrm{g} / \mathrm{ml}$

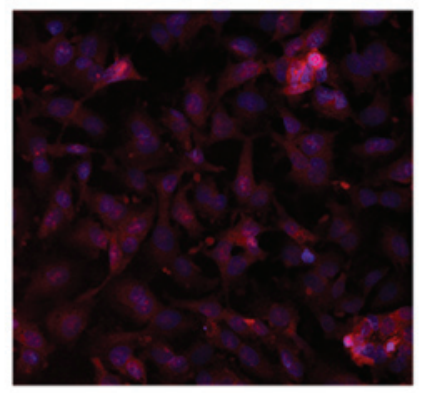

$30 \mu \mathrm{g} / \mathrm{ml}$

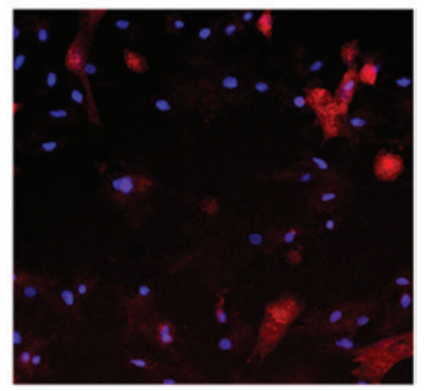

B

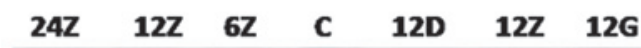

Caspase-3

B-actin

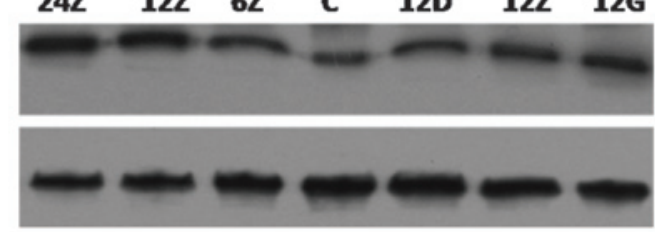

Figure 3. Permeability of mitochondrial membrane regulated in response to salvianolic acid A (Sal A) treatment. A549 was treated with Sal A at 20 and $30 \mu \mathrm{g} /$ $\mathrm{ml}$. At 24-h treatment, cells were stained with MitoTracker ${ }^{\circledR}$ staining, as the control: the cell membrane exhibited bright red color (red arrow), at $20 \mu \mathrm{g} / \mathrm{ml}$, the bright red color was weak and at $30 \mu \mathrm{g} / \mathrm{ml}$, it almost disappeared. (A) Cells became more condensed. (B) Proteins of A549 treated with the same condition as in Fig. 2. Western blot analysis was used to detect the cleaved caspase-3 protein level. The concentrations 24,12 and $6 \mathrm{Z}$ indicate medium dose $(20 \mu \mathrm{g} / \mathrm{ml})$ at 24,12 and $6 \mathrm{~h}$, respectively. C, Control; 12D, $12 \mathrm{Z}$ and $12 \mathrm{G}$ are representative of low $(10 \mu \mathrm{g} / \mathrm{ml})$, medium $(20 \mu \mathrm{g} / \mathrm{ml})$ and high concentrations (30 $\mu \mathrm{g} / \mathrm{ml})$, respectively.

dead (Figs. 2A and B), suggesting that apoptosis is one of the dose-dependent consequences of the Sal A-treated A549.

\section{Sal A increased mitochondrial membrane permeability and the} cleaved caspase-3 protein level. To better understand whether or not the induced apoptosis is mitochondrial-dependent, Thermo Cellomics ${ }^{\circledR}$ ArrayScan ${ }^{\circledR}$ VTi was applied to examine the membrane permeability of A549 cells during Sal A treatment (Fig. 3A). In the control group treated with MitoTracker ${ }^{\circledR}$ staining, the cell membrane exhibited a bright red color. Following the addition of Sal A, the bright red color became weak, indicating that Sal A promoted mitochondrial membrane permeability. Furthermore, at the molecular level, Sal A consistently increased the cleaved caspase-3 protein level (Fig. 3B). 
A

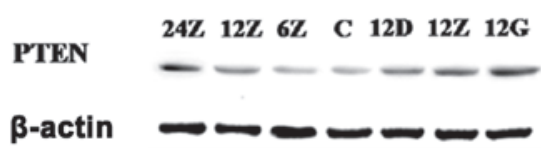

B

$24 Z \quad 12 Z \quad 6 Z$ C $12 D \quad 12 Z 12 G$

P-AKT

B-actin
C

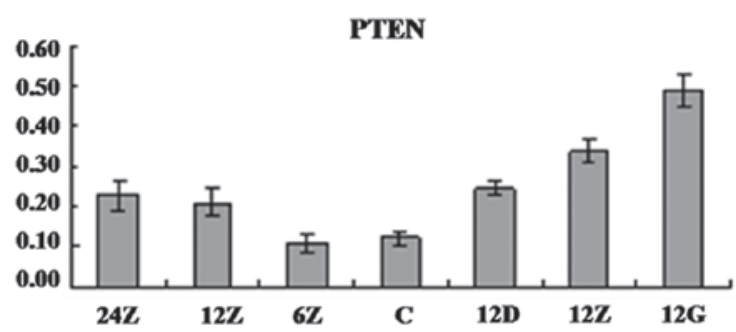

D

P-AKT

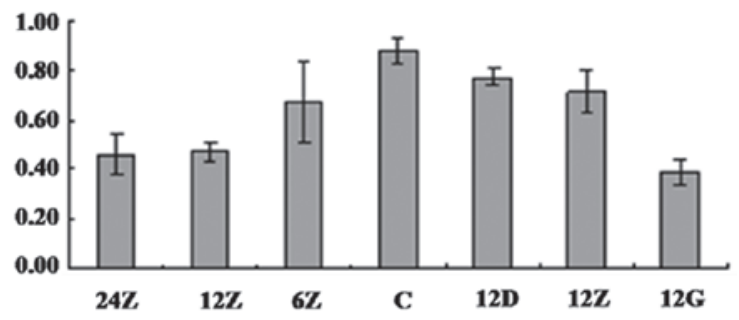

Figure 4. Phosphatase and tensin homolog (PTEN) expression and Akt phosphorylation induced by salvianolic acid A (Sal A). (A) Proteins from A549 were examined by western blot analysis to detect PTEN protein level and (B) Akt phosphorylation at S473. (C) Experiments were repeated three times, the Student's t-test was used to analyze the significance of the protein level, including PTEN and (D) Akt S473. The concentrations 24, 12 and 6Z are representative of medium dose $(20 \mu \mathrm{g} / \mathrm{ml})$ at 24,12 and $6 \mathrm{~h}$, respectively. C, Control; 12D, $12 \mathrm{Z}$ and $12 \mathrm{G}$ are representative of low $(10 \mu \mathrm{g} / \mathrm{ml})$, medium $(20 \mu \mathrm{g} / \mathrm{ml})$ and high concentration $(30 \mu \mathrm{g} / \mathrm{ml})$, respectively.

Sal A upregulated the PTEN protein level and consistently downregulated PI3K/Akt/mTOR signaling pathways. To understand the molecular role of Sal A in regulating A549 cell apoptosis, we examined the PI3K/Akt signaling pathway, which is crucial in regulating cell growth, differentiation and apoptosis. By detecting protein levels using western blot analysis, we found that with Sal A treatment, Akt S473 phosphorylation was downregulated at various time points and Sal A concentrations (Fig. 4). When examining the potential upstream regulation of Akt, we found that the PTEN protein level was upregulated in the same treatment. These results are consistent with cell apoptosis. In addition, to examine whether or not the regulation of PTEN protein level arose from the gene transcription or the protein stability, gene chips and qPCR were performed to examine the PTEN mRNA level (data not shown). The results suggested that at the mRNA level, no significant difference was detected, even at high concentrations of Sal A treatment, indicating that Sal A might positively regulate PTEN protein level through increasing its stability.

\section{Discussion}

Salvia miltiorrhiza is a medical herb that has been used in China as medicine for the treatment of patients with various diseases. Recently, several effective compounds of Salvia miltiorrhiza have been identified as key ingredients in clinical treatments. To the best of our knowledge, our results have demonstrated, for the first time, that Sal A induces apoptosis in human lung cancer cells. Sal A is a hydrophilic molecule and as yet, it is unknown whether its effect is intra- or extracellular. The results of this study demonstrate that this acidic substance has the ability to reduce the viability of lung cancer cells and induce partial apoptosis. The apoptotic rate varied depending on the concentration of Sal A treatment. The medium concentration of Sal A (20 $\mu \mathrm{g} / \mathrm{ml})$ treatment induced a significantly high apoptotic rate. However, at a high concentration of Sal A, cell growth was significantly decreased even though the apoptotic rate was only $6 \%$, suggesting that apoptosis was only one of the consequences of A549 cells responding to Sal A treatment and various cell locations were likely to be interactive.

To further examine the molecular mechanism of Sal A action, we studied the regulation of PI3K/Akt signaling pathway. At the molecular level, the results of repeated experiments suggested that Sal A treatment significantly increased PTEN protein level and consistently decreased phosphorylation of Akt at S473. PTEN expression is reduced in various tumor types, such as lung and breast cancers $(15,16)$. The regulation of PTEN protein level is highly involved in the cell growth. The manner in which the PTEN protein level was upregulated following Sal A treatment remains unknown. Our gene chips and real time PCR did not show any difference of PTEN mRNA level at various time points and Sal A concentrations (data not shown). This observation suggests that Sal A might directly regulate PTEN protein stability, and thus the negative regulation of AKT phosphorylation. However, the manner in which PTEN was modified and its stability regulated has yet to be elucidated. Although apoptosis was only partially regulated, the consequence of Sal A treatment and the positive regulation of PTEN stability in response to Sal A are highly correlated with A549 apoptosis.

\section{Acknowledgements}

This study was supported by a project funded by the Priority Academic Program Development of the Jiangsu Higher Education Institutions and a grant by the National Natural Science Foundation of China (Grant no. 81072777). 


\section{References}

1. Li Z, Zhang W, Zhao Y, et al: Research progress of salvianolic acid A. Zhongguo Zhong Yao Za Zhi 36: 2603-2609, 2011 (In Chinese).

2. Zhang W and Lu Y: Advances in studies on antitumor activities of compounds in Salvia miltiorrhiza. Zhongguo Zhong Yao Za Zhi 35: 389-392, 2010 (In Chinese).

3. Zhang S, Su J and Zhen Y: Salvianolic acid A inhibits nucleoside transport and potentiates the antitumor activity of chemotherapeutic drugs. Yao Xue Xue Bao 39: 496-499, 2004 (In Chinese).

4. Osaki M, Oshimura M and Ito H: PI3K-Akt pathway: its functions and alterations in human cancer. Apoptosis 9: 667-676, 2004.

5. Nielsen-Preiss SM, Silva SR and Gillette JM: Role of PTEN and Akt in the regulation of growth and apoptosis in human osteoblastic cells. J Cell Biochem 90: 964-975, 2003.

6. Koseoglu S, Lu Z, Kumar C, Kirschmeier P and Zou J: AKT1, AKT2 and AKT3-dependent cell survival is cell line-specific and knockdown of all three isoforms selectively induces apoptosis in 20 human tumor cell lines. Cancer Biol Ther 6: 755-762, 2007.

7. Shinji K, Sasazawa Y, Imamichi Y, et al: Caffeine induces apoptosis by enhancement of autophagy via PI3K/Akt/mTOR/ p70S6K inhibition. Autophagy 7: 176-187, 2011.

8. Huang WC and Hung MC: Induction of Akt activity by chemotherapy confers acquired resistance. J Formos Med Assoc 108: 180-194, 2009.

9. Leslie NR and Downes CP: PTEN function: how normal cells control it and tumour cells lose it. Biochem J 382: 1-11, 2004.
10. Chu EC and Tarnawski AS: PTEN regulatory functions in tumor suppression and cell biology. Med Sci Monit 10: RA235-RA241, 2004.

11. Lee JO, Yang H, Georgescu MM, et al: Crystal structure of the PTEN tumor suppressor: implications for its phosphoinositide phosphatase activity and membrane association. Cell 99: 323-334, 1999.

12. Denley A, Gymnopoulos M, Kang S, et al: Requirement of phosphatidylinositol $(3,4,5)$ trisphosphate in phosphatidylinositol 3-kinase-induced oncogenic transformation. Mol Cancer Res 7: 1132-1138, 2009.

13. Degtyarev M, De Mazière A, Orr C, et al: Akt inhibition promotes autophagy and sensitizes PTEN-null tumors to lysosomotropic agents. J Cell Biol 183: 101-116, 2008.

14. Carnero A, Blanco-Aparicio C, Renner O, et al: The PTEN/PI3K/ AKT signaling pathway in cancer, therapeutic implications. Curr Cancer Drug Targets 8: 187-198, 2008.

15. Pappas G, Zumstein LA, Munshi A, et al: Adenoviral-mediated PTEN expression radiosensitizes non-small cell lung cancer cells by suppressing DNA repair capacity. Cancer Gene Ther 14: 543-549, 2007.

16. Kappes H, Goemann C, Bamberger AM, et al: PTEN expression in breast and endometrial cancer: correlations with steroid hormone receptor status. Pathobiology 69: 136-142, 2001. 